\title{
Multiple arterial conduits for bypass grafting: How many are enough?
}

\author{
Harold L. Lazar, MD
}

From the Division of Cardiac Surgery, The Boston University School of Medicine, Boston, Mass.

Disclosures: Author has nothing to disclose with regard to commercial support.

Received for publication April 26, 2016; accepted for publication April 26, 2016; available ahead of print May 24, 2016.

Address for reprints: Harold L. Lazar, MD, 88 East Newton St, Boston, MA 02118 (E-mail: harold.1.lazar@ gmail. com).

J Thorac Cardiovasc Surg 2016;152:870-1

$0022-5223 / \$ 36.00$

Copyright $(2016$ by The American Association for Thoracic Surgery

http://dx.doi.org/10.1016/j.jtcvs.2016.04.082

Recent studies have suggested that patients receiving more than 1 arterial conduit have significantly increased freedom from cardiac death and adverse events, including the incidence of myocardial infarction, recurrent angina, and the need for repeat revascularization. ${ }^{1-3}$ Although improved outcomes have been demonstrated in those patients receiving bilateral internal thoracic arteries (BITAs) versus a single internal thoracic artery and saphenous vein grafts, it has not been conclusively demonstrated that the addition of a third arterial conduit to BITA will confer any additional advantages than can be achieved with BITA + saphenous vein grafts.

In their study, Benedetto and co-workers ${ }^{4}$ found that long-term survival was not significantly improved by using the radial artery as the third arterial conduit in those patients already receiving BITA grafts. There are several strengths to this study. The authors used propensity based scores to obtain 2 equally matched patient cohorts. The radial artery was used appropriately, in that it was grafted to only those vessels with greater than $75 \%$ proximal stenoses. The mean follow-up was 10 years with a significant number of patients followed for as long as 15 years.

However, there were several limitations. The incidence of diabetes mellitus, smoking, chronic obstructive pulmonary disease, and reduced ejection fraction was much lower than seen in contemporary patients undergoing coronary artery bypass grafting. This was reflected in decreased inhospital mortality and postoperative complications that may have contributed to improved long-term survival regardless of the use of a third arterial graft. In addition to being "low risk," this patient cohort was relatively young- $65 \%$ of patients were aged less than 60 years, and only $6 \%$ were aged more than 70 years. Longitudinal analyses such as the present study, which recruited patients over a 19-year period, also must account for changes in surgical techniques and medical therapy. We are not told what the incidence of statins and antiplatelet agents were and whether there were programs instituted for glycemic control or smoking cessation, all of which can influence graft

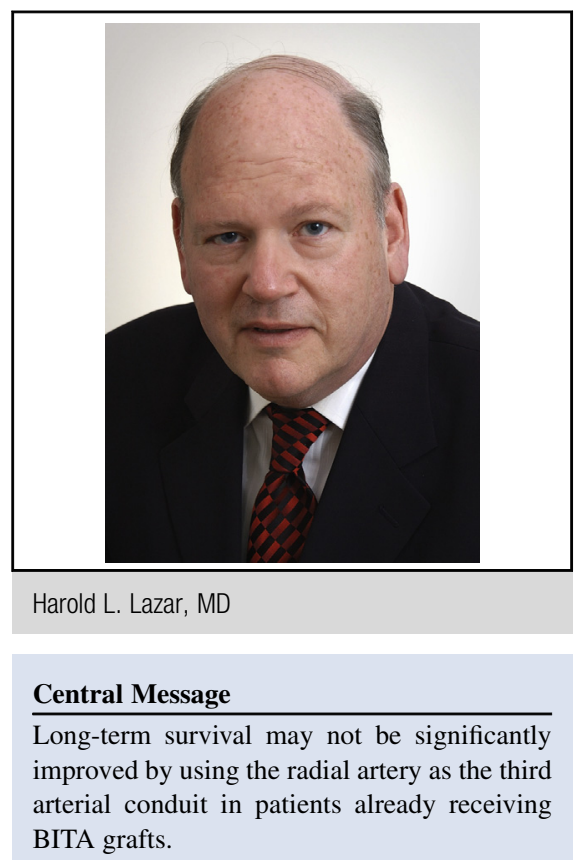

See Article page 862.

patency and progression of atherosclerotic disease. The long-term cause of death, cardiac versus noncardiac, also is not reported. This is important because previous studies have reported the survival benefits of multiarterial grafting occur only in decreasing cardiovascular deaths and may not prolong overall survival.

No mention is made as to the need for recatheterization or graft patency. Furthermore, we are not told about the long-term incidence of recurrent myocardial infarctions, recurrent angina, and need for rehospitalization for acute coronary syndromes. Most important, no data are provided regarding the need for repeat revascularization procedures, coronary artery bypass grafting or percutaneous coronary intervention, between the groups.

Despite these limitations, this study does provide us with important information in determining which patient cohort will benefit from more aggressive arterial grafting. It supports previous studies that have shown that additional arterial grafts in patients already receiving BITA result in no significant improvement in clinical outcomes. ${ }^{1-3}$ Further studies will be necessary to determine whether multiple arterial grafting will improve outcomes in older patients ( $>70$ years), those with multiple comorbidities, patients with reduced ejection fractions $(<40 \%)$, and those 
with more diffuse distal disease. Only then can we answer the question involving multiple arterial conduits for bypass grafting: How many are enough?

\section{References}

1. Nasso G, Popoff G, Lamarra M, Romano V, Coppola R, Bartolomucci F, et al. Impact of arterial revascularization in patients undergoing coronary bypass. J Card Surg. 2012;27:427-33.
2. Kieser TM, Lewin AM, Graham MM, Martin BJ, Galbraith DD, Rabi CM, et al Outcomes associated with bilateral internal thoracic artery grafting: the importance of age. Ann Thorac Surg. 2011;92:1269-75.

3. Toumpoulis IK, Anagnostopoulus CE, Balaram S, Swistel DG, Ashton RC DeRose JJ. Does bilateral internal thoracic artery grafting increase long-term survival of diabetic patients? Ann Thorac Surg. 2006;81:599-607.

4. Benedetto U, Caputo M, Zakhar M, Bryan A, Angelini GD. Are three arteries better than two? Impact of using the radial artery in addition to bilateral internal thoracic artery on long-term survival. J Thorac Cardiovasc Surg. 2016;152:862-9. 